\title{
India agrees to new terms on rocket contract with Russia
}

New Delhi. A controversial deal over cryogenic engines between India and the former Soviet Union has been renegotiated, ending a long period of suspense over the fate of the geostationary launch vehicle (GSLV), India's biggest rocket which is designed to launch commercial satellites into geostationary orbit

The original contract, agreed in 1991, involved the supply of two cryogenic upper stages for the GSLV, together with the technology for local manufacture in India. But the deal had been hanging fire since the break-up of the Soviet Union, as Russia had come under pressure from the United States to cancel it (see Nature 364, 371; 1993).

U. R. Rao, the chief of the Indian Space Research Organization (ISRO), announced last week that a renegotiated contract between the ISRO and the Russian space company Glavkosmos has now been approved by both governments.

The new terms will be welcomed by US officials, as Russia will not transfer to the Indians the know-how for building cryogenic engines. The United States had feared that India might use this technology for making military missiles, but had not objected to Russia selling assembled engines.

Under the new contract, India will receive four ready-to-fly cryogenic upper stages, and two 'mock-up' versions, for the previously agreed price of $\$ 80$ million. In addition, ISRO has an option to buy up to three additional cryogenic engines at a cost of \$3 million each.

Overall, says Rao, India will receive seven cryogenic stages, with the first delivered in June 1996, to be followed by one every six months. ISRO is planning the first test launch of the GSLV powered by the Russian engine to take place in 1997

The deal will provide much-needed capital for the Russian space company, which has already received more than half of the sum agreed in the contract. But ISRO has lost out. "We went in for the contract to get hold of the technology, not just ready-made engines," says one top scientist involved in the organization's \$120 million project to develop an indigenous cryogenic engine.

With the GSLV design already frozen, the ISRO project will now be constrained by the fact that the indigenous engine must have the same specifications as the Russian engine. But Rao remains confident that ISRO's own engine will be ready for testing by 1998 at the latest. To achieve this, ISRO hopes to take advantage of the lengthy training that its engineers have already received in Russia, as well as the design drawings which were obtained under the original contract.

K. S. Jayaraman

\section{Study confirms AZT's lack of prophylactic effect}

London. Azidothymidine (AZT), otherwise known as Zidovudine, is not an effective prophylactic of AIDS when used in people infected with human immunodeficiency virus (HIV), but in whom symptoms of AIDS have not yet appeared.

That is the final conclusion of the socalled Concorde study mounted by Britain, France and Ireland in 1988 in the wake of the decision by the US Food and Drug Administration (FDA) to license the prophylactic use of AZT.

A preliminary report on the Concorde trial, foreshadowing the final conclusion, was published last year (The Lancet 341, $889-890 ; 1993)$. As a result, the conclusions of last week's publication (The Lancet 343, $871-881$; 1994) have been partly anticipated by both physicians and the stock-markets.

But the final report should quell controversies over the apparent disagreement between the Concorde trial, to which 1,719 symptomless people with HIV infection were recruited, and a handful of smaller trials, some of which suggest that the early use of AZT could be beneficial.

The Concorde Coordinating Committee now says that its conclusions are consistent with those of the earlier smaller studies notably in the United States and Australia once allowance has been made for the smaller size of other studies, their short duration, or their use of the $\mathrm{CD} 4^{+}$cell-count as a proxy for clinical improvement.

\section{Newspaper revives anti-HIV claims}

London. The London Sunday Times has rediscovered AIDS. In an article headed "Conspiracy of Silence" on 3 April, the newspaper's science correspondent, Neville Hodgkinson, describes a "large and growing network" of "highly qualified" people who dissent from the "HIV hypothesis" and are willing to admit it.

The reference appears to be to the signatories of an open letter organized three years ago by Charles Thomas, now at the California State University at San José, appealing for a reappraisal. Kary Mullis, the inventor of the polymerase chain reaction (PCR) and last year's Nobel prizewinner in chemistry, one of the signatories, is quoted as saying that "the HIV hypothesis is unfalsifiable, and useless as a medical hypothesis".

The report also says that Nature has sought to dissuade the Sunday Times from "reporting evidence that HIV is probably not the cause of AIDS", and asserts that scientists "have to be careful not to rock
On this last point, the Concorde report suggests that early administration of AZT increases the concentration of $\mathrm{CD} 4^{+}$cells in the blood of symptomless patients, at least for the three-year period during which their condition was followed.

But the study found no significant difference between the death or disease rates among those given AZT at the outset of the trial, and those in whom its use was delayed until the appearance of symptoms.

Although originally designed as a double-blind study, in which neither patients nor their physicians would know whether they were in the control or study groups, physicians were allowed to put their patients on AZT if $\mathrm{CD}^{+}$cell-counts were low, or if symptoms of AIDS appeared.

Over three years, a total of 418 people or a quarter of the total - became aware of their treatment for these reasons. But the final report insists that this does not undermine its conclusions.

The report also presents preliminary data on the side-effects associated with the administration of AZT. Apart from 6 people who died from medical conditions not obviously linked with treatment in the trial, 99 people in the treatment group, and 38 among those given placebos, stopped taking trial capsules for a variety of reasons, including gastro-intestinal difficulties, persistent headaches and declining haemoglobin levels.

John Maddox

the HIV boat, which carries jobs, reputations and huge research funds".

It concludes with a statement by Hiram Caton, described as head of the school of applied ethics at Griffith University, New South Wales, that when "no vaccine will be forthcoming", scientists will "have to come to terms with the awful fact that the AIDS epidemic was a mirage."

A week later, on 10 April, the newspaper continued its campaign with a report of the results of the Concorde trial (see above). It quotes Peter Duesberg as saying that "When the time is ripe to say that AZT is detrimental, that it actually hurts, the interpretation will change again".

In the same issue, Hodgkinson describes a recent finding that $\mathbf{4 2}$ per cent of people attending an AIDS clinic in London had used amyl nitrite as an aphrodisiac within the previous month. The introduction to the article says that this "new evidence" shows that amyl nitrite is "an important cause of AIDS". 